\title{
GENE THERAPY IN LUNG TRANSPLANTATION: EFFECTIVE GENE TRANSFER VIA THE AIRWAYS
}

\author{
Anders Jeppsson, MD \\ Ronald Lee, $\mathrm{MS}^{\mathrm{a}}$ \\ Carlo Pellegrini, $\mathrm{MD}^{\mathrm{a}}$ \\ Timothy O'Brien, MD, $\mathrm{PhD}^{\mathrm{b}}$ \\ Henry D. Tazelaar, $\mathrm{MD}^{\mathrm{c}}$ \\ Christopher G. A. McGregor, MB, \\ FRCS $^{\mathrm{a}}$
}

\begin{abstract}
Objectives: Gene therapy may provide a means of modifying factors that contribute to the development of pathologic processes in transplanted lungs. Experiments were designed to study the feasibility of adenovirusmediated gene transfer by way of the airways to the transplanted lung. Methods: Orthotopic left lung transplantation (Lewis to Lewis rats) was performed on four groups of animals. $300 \mu$ l of adenovirus solution encoding for $\beta$-galactosidase was infused into the left bronchus of donor rats at viral concentrations of $10^{8} \mathrm{pfu} / \mathrm{ml}(n=5), 10^{9} \mathrm{pfu} / \mathrm{ml}(n=6)$, and $10^{10} \mathrm{pfu} / \mathrm{ml}(n=6)$, and the lung was ventilated for 5 minutes. Controls $(n=6)$ received medium only. Seven days after transplantation, native and transduced, transplanted lungs were harvested. Sections of lung were fixed and stained with a solution of X-Gal (5-bromo-4-chloro-3-indolyl- $\beta$-Dgalactopyranoside) and staining was evaluated for distribution by cell type and intensity. Results: $\beta$-Galactosidase expression was absent in the control group and in the native lungs. Two of five lungs in the $10^{8}$ group expressed $\beta$-galactosidase, but in a limited distribution and intensity. All six lungs in the $10^{9}$ group and five of six lungs in the $10^{10}$ group expressed $\beta$-galactosidase. The distribution and intensity of $\beta$-galactosidase expression ranged from only a few cells staining per slide to up to $75 \%$. Pneumocytes were the most frequently stained cell type followed by alveolar macrophages. Conclusions: Gene transfer to the transplanted lung via the bronchial route is feasible and offers a novel technique to modify pathologic processes in the transplanted lung. (J Thorac Cardiovasc Surg 1998;115:638-43)
\end{abstract}

L ung transplantation is an accepted treatment for selected patients with end-stage pulmonary disease. Current survival is $70 \%$ at 1 year and $45 \%$ at 5 years. ${ }^{1}$ Although early results have improved after lung transplantation, significant long-term attrition occurs. Postoperative complications include acute

From the Departments of Surgery, ${ }^{\mathrm{a}}$ Endocrinology, ${ }^{\mathrm{b}}$ and Laboratory Medicine and Pathology, ${ }^{\mathrm{c}}$ Mayo Clinic and Foundation, Rochester, Minn.

This work was supported by the Mayo Clinic and Foundation, Rochester, Minnesota, and the Bruce and Ruth Rappaport Program in Vascular Biology. Dr Anders Jeppsson is a visiting scientist supported by grants from University of Gothenburg, Assar Gabrielsson Foundation, Swedish Medical Society, Swedish Medical Research Council and Gothenburg Medical Society.

Received for publication May 22, 1997; revisions requested July 15, 1997; revisions received August 13, 1997; accepted for publication Sept. 22, 1997.

Address for reprints: C. G. A. McGregor, MB, FRCS, 6-716 Mary Brigh D, Saint Marys Hospital, Mayo Clinic, Rochester, MN 55905 .

Copyright (C) 1998 by Mosby, Inc.

$0022-5223 / 98 \$ 5.00+0 \quad \mathbf{1 2} / \mathbf{1} / \mathbf{8 6 3 3 8}$ and chronic rejection, infection, and the side effects of immunosuppressive treatment.

Emerging gene therapy techniques provide a potential novel method of controlling these processes at a molecular level. Adenoviral-mediated gene transfer has been used to obtain efficient gene transfer and expression in different cells, tissues, and organs, including transplanted hearts ${ }^{2-4}$ and recently to lung grafts by way of the pulmonary artery. ${ }^{5}$ One advantage of adenoviral vectors for gene transfer is the ability to transduce nonreplicative cells. Adenoviral vectors can be grown to high titer and are usually not incorporated into the host cell genome, ${ }^{6}$ thus avoiding the risk of insertional mutagenesis. Disadvantages of adenoviral-mediated gene transfer include cytotoxicity, limited duration of expression, and the inability to administer a second dose because of an immune response. ${ }^{6}$

In nontransplanted lungs, adenovirus-mediated gene transfer by way of the airways has been reported. ${ }^{7,8}$ In contrast, gene transfer to the transplanted lung by way of the airways has not been reported. 
The addition of a major operation and cold ischemia to the organ make observations obtained under nontransplant conditions unreliable in the setting of organ transplantation. We hypothesized that adenovirus-mediated gene transfer to lung grafts might be feasible using a bronchial route of administration.

\section{Methods}

Animals. Forty-six inbred Lewis rats (Harlan Sprague Dawley, Inc., Indianapolis, Ind.), weighing 250 to $320 \mathrm{gm}$ were used in the experiments. Animal care was conducted in accordance with the "Principles of Laboratory Animal Care" formulated by the National Society for Medical Research and the "Guide For the Care and Use of Laboratory Animals" prepared by the National Institutes of Health (NIH Publication No. 86.23, revised 1985).

Adenovirus vector. A replication defective adenovirus vector encoding for $\beta$-galactosidase $(\beta$-gal) under the control of the cytomegalovirus promoter (AdCMVLacZ, a kind gift from James Wilson, Institute for Human Gene Therapy, University of Pennsylvania) was used as the reporter gene. The adenoviral vector is a first-generation, serotype 5, E1-E3 deleted vector. ${ }^{9}$ The recombinant virus was propagated in 293 cells and then isolated and purified. Viral titers were determined by plaque assay and expressed as plaque-forming unit per milliliter ( $\mathrm{pfu} / \mathrm{ml}$ ). Three hundred microliters of the viral solution (diluted in $2 \%$ fetal calf serum in 199 medium) was used in all viral transductions. Control animals received the same volume of medium. The volume for bronchial infusion was determined in preliminary experiments in which medium stained with Evans blue dye was infused into the left bronchus until the left lung became fully stained, and the injected volume was measured.

Experimental groups. Donor rats were divided into three groups receiving different concentrations of the viral solution. The first group $(n=5)$ received a viral dose of $1 \times 10^{8} \mathrm{pfu} / \mathrm{ml}$, the second group $(n=6) 1 \times 10^{9} \mathrm{pfu} / \mathrm{ml}$, the third group $(n=6) 1 \times 10^{10} \mathrm{pfu} / \mathrm{ml}$. A fourth group $(n=6)$ of transplanted rats received medium only and served as control animals. The viral administration and transplantation was first accomplished in four animals in the $10^{9} \mathrm{pfu} / \mathrm{ml}$ group followed by four in the $10^{10}$ group, four in $10^{8}$ group, and four control animals. After this, the remaining animals were transplanted in random order.

Gene transfer and transplantation. After anesthesia, the donor rat was intubated and ventilated (Harvard Rodent Ventilator, Harvard Apparatus Co., Inc., S. Natick, Mass.). A median sternotomy was performed to expose the lungs. After dissection of the hilum, the rat was given 100 units of aqueous heparin injected into the inferior vena cava. The tidal volume was reduced to $50 \%$ and the right bronchus occluded. The viral solution (300 $\mu l)$ was instilled in the left bronchus without pressure. The lung was ventilated for 5 minutes to allow distribution of virus. The clamp on the right bronchus was released and the right atrium was opened. Twenty milliliters of pneumoplegia (Euro-Collins solution) was infused in the main pulmonary artery and the heart-lung block was explanted. The lung was stored for 1 hour in Euro-Collins solution at $4^{\circ} \mathrm{C}$ before implantation to mimic conditions during clinical lung transplantation. In the recipient, a left thoracotomy was performed and the left lung was dissected and removed. The preserved, transduced donor left lung was then implanted orthotopically into the recipient by anastomosing the pulmonary vein and artery. The lung was reperfused, after which the bronchus was anastomosed. All anastomoses were performed with 10-0 monofilament sutures. The chest wall was closed with a small chest tube in situ, which was removed during recovery from anesthesia.

Lung retrieval and histochemical analysis. Seven days after transplantation, native and transplanted lung, spleen, kidney, and liver were harvested. Cross sections from the midsection of the organs were embedded in optimal cutting temperature (OCT compound) and snap frozen in liquid nitrogen. Five $5 \mu \mathrm{m}$ thick cryostat sections were cut at $25 \mu \mathrm{m}$ intervals. The specimens were fixed in $1.25 \%$ glutaraldehyde for 10 minutes at $4^{\circ} \mathrm{C}$ and rinsed three times with phosphate-buffered saline (PBS) solution. The sections were then stained in a solution of 5-bromo-4-chloro-3-indolyl- $\beta$-D-galactopyranoside (XGal); Boehringer Mannheim Corp., Indianapolis, Ind.) for 4 hours at $37^{\circ} \mathrm{C}$. The X-Gal-stained specimens were then rinsed in PBS and counterstained with eosin. Blue cells indicated the presence of $\beta$-gal expression. Adjacent slides were stained with hematoxylin and eosin for routine histopathologic examination.

The distribution of transgene expression was evaluated by an observer blinded to the origin of the slides, examining X-Gal staining in the lung by cell type (pneumocytes, macrophages, endothelial and airway epithelial cells). Transgene expression was quantified using the following scoring system: $0 \%$ of cells staining $=0,1 \%$ to $25 \%$ staining $=1,26 \%$ to $50 \%$ staining $=2,51 \%$ to $75 \%$ staining $=3$, and $>75 \%$ staining $=4$, and staining intensity as pale $(=1)$ or dark $(=2)$. Five slides in each animal were evaluated and the mean calculated. The number of transduced cells represent the average of all animals in the respective group.

Statistical analysis. Staining scores are expressed as mean and standard error of the mean. The Kruskal-Wallis test followed by individual Wilcoxon rank sum test was used to evaluate differences between the groups. ${ }^{10} \mathrm{~A} p$ value of less than 0.05 was considered significant.

\section{Results}

Mortality. The perioperative mortality in the study was $20 \%$. Only surviving animals were included in the study.

Distribution of transgene expression. Transgene expression was detected in transduced, transplanted lungs at a level and intensity outlined in Table I. Pneumocytes were the most frequently stained cell type with up to $80 \%$ of the cells staining in a particular section, followed by alveolar macrophages (Table I). Transgene expression was demonstrated in small numbers of endothelial and bron- 

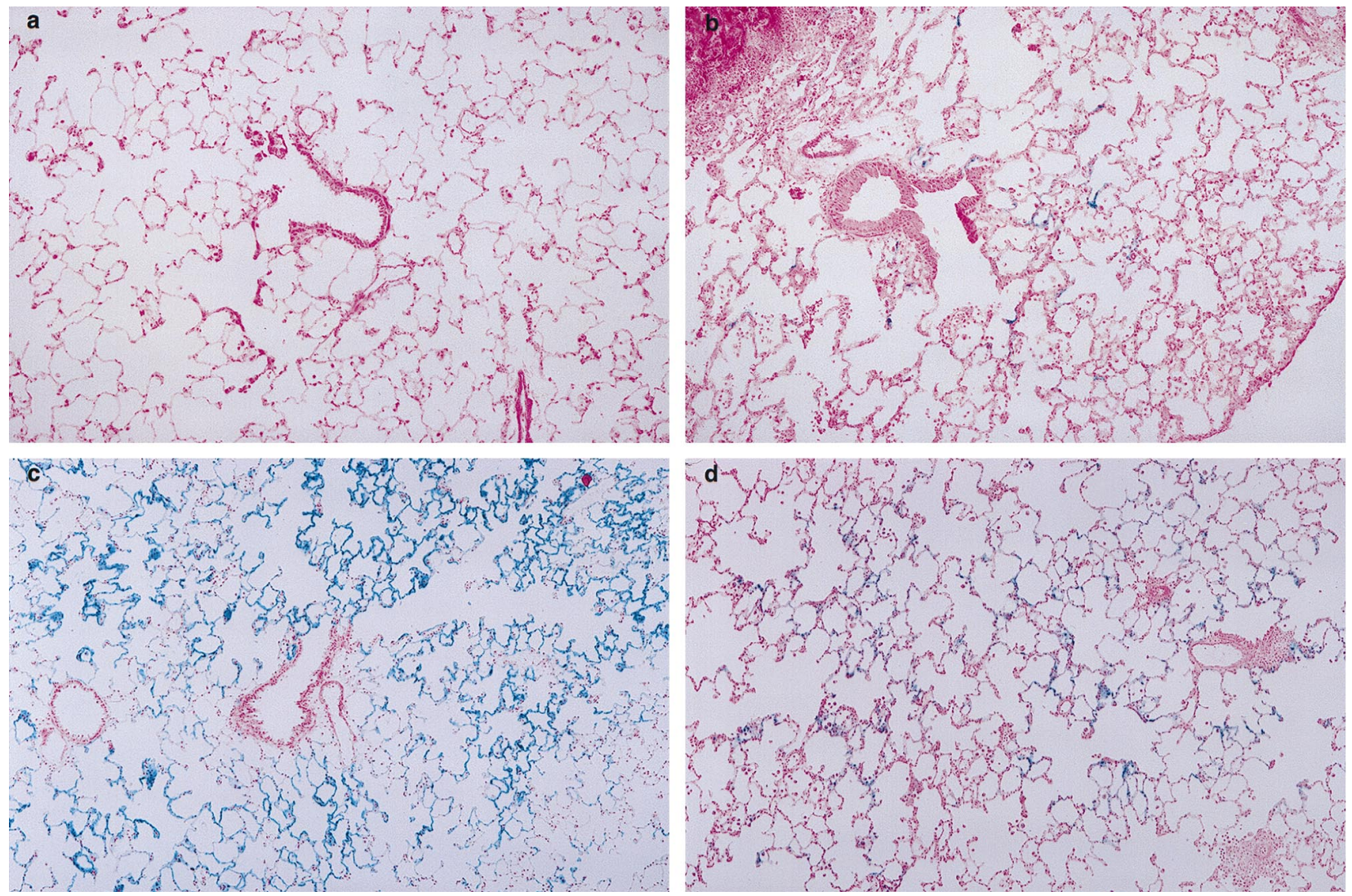

Fig. 1. Sections of transplanted lung from the control group (a), the $10^{8} \mathrm{pfu} / \mathrm{ml}$ group (b), the $10^{9} \mathrm{pfu} / \mathrm{ml}$ group (c), and the $10^{10} \mathrm{pfu} / \mathrm{ml}$ group (d). $\beta$-Galactosidase expression is indicated by the blue-stained cells.

Table I. Staining number and intensity scores (mean \pm SEM) for different cell types in the control group and in the $10^{8}, 10^{9}$ and $10^{10} \mathrm{pfu} / \mathrm{ml}$ groups

\begin{tabular}{|c|c|c|c|c|c|c|c|c|}
\hline & \multicolumn{2}{|c|}{ Controls } & \multicolumn{2}{|c|}{$10^{8}$} & \multicolumn{2}{|c|}{$10^{9}$} & \multicolumn{2}{|c|}{$10^{10}$} \\
\hline & Number & Intensity & Number & Intensity & Number & Intensity & Number & Intensity \\
\hline Pneumocytes & 0 & 0 & $0.2 \pm 0.2$ & $0.2 \pm 0.2$ & $1.7 \pm 0.5$ & $1.3 \pm 0.3$ & $1.7 \pm 0.5$ & $1.3 \pm 0.3$ \\
\hline Endothelial cells & 0 & 0 & 0 & 0 & 0 & 0 & $0.2 \pm 0.2$ & $0.2 \pm 0.2$ \\
\hline Airway epithelial cells & 0 & 0 & 0 & 0 & $0.03 \pm 0.03$ & $0.03 \pm 0.03$ & 0 & 0 \\
\hline Macrophages & 0 & 0 & 0 & 0 & $0.2 \pm 0.2$ & $0.2 \pm 0.2$ & $0.4 \pm 0.2$ & $0.3 \pm 0.2$ \\
\hline
\end{tabular}

SEM, Standard error of the mean.

Transgene expression was quantified using the following scoring system: $0 \%$ of cells staining $=0,1 \%$ to $25 \%$ staining $=1,26 \%$ to $50 \%$ staining $=2,51 \%$ to $75 \%$ staining $=3$, and $>75 \%$ staining $=4$, and staining intensity as pale $(=1)$ or dark $(=2)$.

chial epithelial cells. $\beta$-Gal was not detected in the control group (Fig. 1, $a$ ).

Effect of dose of vector. Two of five transplanted lungs in the $10^{8}$ group expressed $\beta$-gal but with a limited distribution and intensity (Fig. 1, b). $\beta$-Gal expression was detected in all six transplanted lungs in the $10^{9}$ group (Fig. 1, c). In the $10^{10}$ group, five of six transplanted lungs expressed $\beta$-gal (Fig. $1, d$ ). In pneumocytes (Fig. 2), a significant difference in staining number score was observed between the $10^{8}$ group and the $10^{9}$ and $10^{10}$ groups with KruskalWallis test (overall $p$ value 0.04 ) followed by individual Wilcoxon rank sum test $(p=0.03$ and $p=$ 0.04 , respectively). After Bonferroni adjustment, the $p$ values reached borderline significance ( $p=0.06$ and $p=0.09$, respectively).

Expression in distant organs. To assess expression in distant organs $\mathrm{X}-\mathrm{Gal}$ staining was performed 


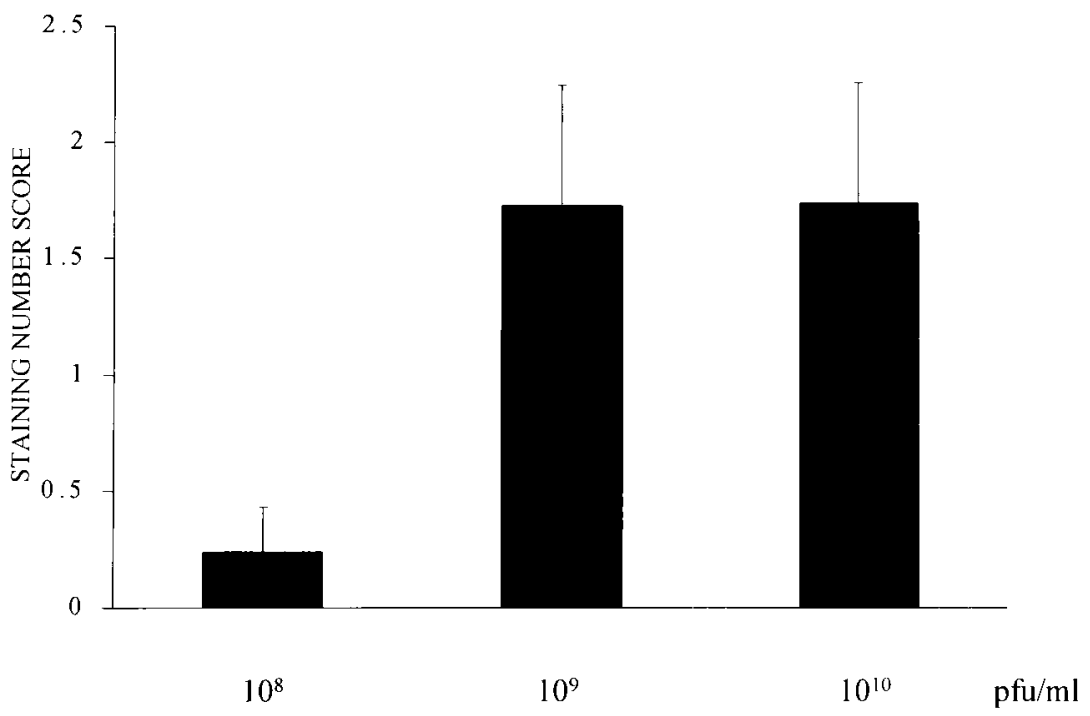

Fig. 2. Staining number scores in pneumocytes (mean \pm SEM) in the $10^{8} \mathrm{pfu} / \mathrm{ml}$ group, the $10^{9} \mathrm{pfu} / \mathrm{ml}$ group, and the $10^{10} \mathrm{pfu} / \mathrm{ml}$ group. A significant difference can be observed between the $10^{8} \mathrm{pfu} / \mathrm{ml}$ group and the $10^{9}$ and the $10^{10} \mathrm{pfu} / \mathrm{ml}$ group ( $p=0.03$ and $p=0.04$, respectively).

in native lung, spleen, liver, and kidney of transplanted animals. We were unable to detect transgene expression in any of the tissues examined.

Vector toxicity. Histopathologic examination of hematoxylin and eosin-stained lung slides cut immediately adjacent to the slides stained for X-Gal, showed signs of mild, patchy, chronic inflammation (lymphocytes and macrophages) in three animals in the $10^{10}$ group and in one animal in the $10^{9}$ group, whereas in the other animals no inflammation was seen. In the $10^{8}$ group and in the control group no lungs showed any inflammation. No correlation between the efficiency of gene transfer and the presence of inflammation was found.

\section{Discussion}

Transplantation, with the opportunity to pretreat the donor organ at the time of harvest, provides a unique opportunity for genetic modification of the graft. In the future, introduction of genes encoding for biologically active compounds, which influence the immunologic or physiologic reactivity of the bronchial airways and vessels, may offer a novel approach to modify pathologic processes in the transplanted lung. In this study we show for the first time that efficient gene transfer to the transplanted lung by way of the airways is feasible by use of an adenovirus vector.

Recently, Chapelier and colleagues ${ }^{5}$ reported ad- enovirus-mediated gene transfer to transplanted lungs in pigs with pulmonary artery administration of a high concentration of vector $\left(2 \times 10^{11} \mathrm{pfu} / \mathrm{ml}\right){ }^{5}$ This method resulted in a rather low transduction rate, which is in accordance with previous nontransplant studies that used pulmonary artery administration. ${ }^{11,12}$ Even though comparisons between different species are problematic, this study indicates that airway administration may increase the efficiency of adenovirus-mediated gene transfer to the transplanted lung. However, transduction in this study was restricted mainly to pneumocytes, which may limit the use of a solution administered by way of the airways if the disease target is predominantly in the airways. In contrast, Janssens and colleagues ${ }^{8}$ reported efficient gene transfer after aerosolized delivery of an adenoviral vector to all pulmonary cells, including airway epithelial cells.

In these experiments we observed considerable variability in the efficiency of gene transfer. Indeed, in one animal in the group transgene expression was not detected. We are unclear as to the reason for this observation but believe that it is due to biologic variability of gene transfer. It is obviously, however, an issue that needs to be addressed by further studies.

In this study viral transduction appeared to be more effective at higher viral concentrations $\left(10^{9}\right.$ and $10^{10} \mathrm{pfu} / \mathrm{ml}$ compared with $\left.10^{8} \mathrm{pfu} / \mathrm{ml}\right)$. How- 
ever, no difference was observed between $10^{9}$ and $10^{10} \mathrm{pfu} / \mathrm{ml}$, suggesting that no advantage may be found to using higher doses than $10^{9} \mathrm{pfu} / \mathrm{ml}$. Use of the lowest effective dose of vector may be important in reducing viral toxicity. Because the virus solution is left in the lung after transplantation, virus may enter the systemic circulation at that time. However, we could not detect transgene expression in liver, kidney, or spleen 1 week after transplantation with these doses of vector. This does not, however, exclude low levels of transgene expression because $\beta$-gal staining may not be sensitive enough for this purpose.

We have previously described gene transfer to the transplanted heart. ${ }^{4}$ In contrast with the observations in that study, transgene expression appeared to be higher in the transplanted lung with the same concentrations of vector. This may be a result of a higher affinity of adenovirus for pneumocytes than myocytes or may result from the technique of administration or a combination of both. The bronchial administration route allows transduction at normal body temperature in a perfused, oxygenated lung. In contrast, gene transfer to the transplanted heart during cold ischemia may be less efficient. Data are conflicting as to whether adenovirus-mediated gene transfer is temperature dependent. Gene transfer to endothelial cells in vitro was reported by Chapelier and colleagues ${ }^{5}$ to be better at $37^{\circ} \mathrm{C}$ compared with $10^{\circ} \mathrm{C}$, whereas Merrick and colleagues $^{13}$ concluded that gene transfer to endothelial cells in cell and organ cultures was not influenced by temperature. Csete and colleagues ${ }^{14}$ reported a transduction rate of up to $80 \%$ of hepatocytes in liver grafts transducted at $4^{\circ} \mathrm{C}$, indicating that adenoviral affinity may be more important than temperature. No study analyzing the effect of temperature dependence in vivo has been reported and will be difficult to perform in the setting of transplantation because the donor organs require cold storage for preservation during the inevitable ischemia before implantation.

The efficiency of adenoviral-mediated gene transfer to airway epithelial cells is unclear. It has been reported that adenovirus has a natural affinity for bronchial epithelial cells ${ }^{15}$ and that regenerating epithelial cells are a preferential target for adenovirus. ${ }^{16}$ In contrast, a study from Zabner and colleagues ${ }^{17}$ indicates that adenoviral-mediated gene transfer to differentiated bronchial cells is extremely inefficient. In this study rare bronchial and bronchiolar epithelial cells expressed $\beta$-gal, which may be due to the delivery method. After the virus was delivered to the bronchus, the lung was ventilated for 5 minutes and this may have resulted in delivery of the vector predominantly to the alveoli. Therefore the dwell time in the airways may have been too brief to result in efficient gene transfer to airway epithelial cells.

The lack of gene expression to airway epithelium suggests that additional alternative methods of delivery may need to be explored to treat or prevent pathologic processes in the bronchus and bronchioles. Obliterative bronchiolitis is the major cause of mortality after lung transplantation, with an incidence of $45 \%$ to $55 \%$ in patients surviving more than 1 year. ${ }^{1}$ The hope would be in the future that prevention or treatment of obliterative bronchiolitis by delivery of genes encoding for antiproliferative substances may be possible in the setting of lung transplantation.

In summary, this study shows that adenovirusmediated gene transfer by way of the airways to the transplanted lung is feasible. This may offer new possibilities to modify pathologic processes in the transplanted lung.

\section{REFERENCES}

1. Hosenpud JD, Novick RJ, Breen TJ, Keck B, Daily P. The Registry of the International Society for Heart and Lung Transplantation: Twelfth Official Report-1995. J Heart Lung Transplant 1995;14:805-15.

2. Ardehali A, Fyfe A, Laks H, Drinkwater DC, Qiao JH, Lusis AJ. Direct gene transfer into donor hearts at the time of harvest. J Thorac Cardiovasc Surg 1995;109:716-9.

3. Lee J, Laks H, Drinkwater DC, et al. Cardiac gene transfer by intracoronary infusion of adenovirus vector-mediated reporter gene in the transplanted mouse heart. J Thorac Cardiovasc Surg 1996;111:246-52.

4. Yap J, O'Brien T, Tazelaar HD, McGregor CGA. Immunosuppression prolongs adenoviral mediated transgene expression in cardiac allograft transplantation. Cardiovasc Res 1997;35:529-35.

5. Chapelier A, Danel C, Mazmanian M, Bacha EA, Sellak H, Gilbert MA, et al. Gene therapy in lung transplantation: feasibility of ex vivo adenovirus-mediated gene transfer to the graft. Hum Gene Ther 1996;7:1837-45.

6. Schneider MD, French BA. The advent of adenovirus. Gene therapy for cardiovascular disease. Circulation 1993;88:193742.

7. Mastrangeli A, Danel C, Rosenfeld MA, et al. Diversity of airway epithelial cell targets for in vivo recombinant adenovirus-mediated gene transfer. J Clin Invest 1993;91:225-34.

8. Janssens SP, Bloch KD, Nong Z, Gerard RD, Zoldhelyi P, Collen D. Adenoviral-mediated transfer of the human endothelial nitric oxide synthase gene reduces acute hypoxic pulmonary vasoconstriction in rats. J Clin Invest 1996;98:31724.

9. Yang Y, Raper SE, Cohn JA, Engelhardt JF, Wilson JM. An 
approach for treating the hepatobiliary disease of cystic fibrosis by somatic gene transfer. Proc Natl Acad Sci U S A 1993;90:4601-5.

10. Mehta CR, Patel NR, Tsiatis AA. Exact significance testing for ordered categorical data. Biometrics 1984;40: 819-25.

11. Schachtner SK, Rome JJ, Hoyt RF, Newman KD, Virmani R, Dichek DA. In vivo adenovirus-mediated gene transfer via the pulmonary artery of rats. Circ Res 1995;76:701-9.

12. Lemarchand P, Jones M, Danel C, Yamada I, Mastrangeli A, Crystal RG. In vivo adenovirus-mediated gene transfer to lungs via pulmonary artery. J Appl Physiol 1994;76: 2840-5.

13. Merrick AF, Shewring LD, Sawyer GJ, Gustafsson KT, Fabre JW. Comparison of adenovirus gene transfer to vascular endothelial cells in cell culture, organ culture and in vivo. Transplantation 1996;62:1085-9.

14. Csete ME, Drazan KE, van Bree M, et al. Adenovirusmediated gene transfer in the transplant setting. I. Conditions for expression of transferred genes in cold-preserved hepatocytes. Transplantation 1994;57:1502-7.

15. Ali M, Lemoin NR, Ring CJ. The use of DNA viruses for gene therapy. Gene Therapy 1994;1:367-84.

16. Dupuit F, Zahm JM, Brezillon S, et al. Regenerating cells in human airway surface epithelium represent preferential targets for recombinant adenovirus. Hum Gene Ther 1995;6: 1185-93.

17. Zabner J, Zeiher BG, Friedman E, Welsh MJ. Adenovirusmediated gene transfer to ciliated airway epithelia requires prolonged incubation time. J Virol 1996;70:6994-7003. 